\title{
STRANDEDNESS OF VICIA FABA \\ CHROMOSOMES AS REVEALED \\ BY ENZYME DIGESTION STUDIES
}

\author{
JAMES E. TROSKO, Ph.D., and SHELDON WOLFF, Ph.D. \\ From the Biology Division, Oak Ridge National Laboratory, Oak Ridge, Tennessee
}

\begin{abstract}
Chromosomes and nuclei isolated from neutral formalin-fixed Vicia faba lateral roots were treated with trypsin, pepsin, RNase, or DNase. Only trypsin affected the morphology of the chromosomes and nuclei. The appearance of the chromosomes after trypsin digestion indicated that each chromatid contained four strands that could be seen with an ordinary light microscope. The experiments are interpreted as indicating that mitotic chromosomes of Vicia faba are multistranded and that the linear continuity of the chromosome is dependent on protein.
\end{abstract}

\section{INTRODUCTION}

Although we know that the chromosomes of higher organisms, i.e., the eucaryotes of Ris and Chandler (29), consist of nucleic acids and proteins, we do not yet know the architectural relations of the chromosomes' component molecules. Because of this lack of precise knowledge regarding chromosome structure, many models have been postulated from a variety of experimental results. Some of these models show the chromosome with a backbone, which may or may not be protein, from which the deoxyribonucleic acid (DNA) extends (40). In other models the linear continuity of the chromosome is maintained by DNA $(41,43)$. The models differ more grossly in that some represent a chromosome as consisting of several units that are repeated laterally (i.e., a multistranded chromosome, see references $13,28,37$ ), whereas others represent a chromosome as being single stranded. The reason for this difference in postulated gross chromosomal anatomy is that different experimental procedures have led to observations that are compatible with either a multistranded or a single-stranded chromosome. For instance, anaphase chromosomes have repeatedly been observed to be split into two chromatids (see 28 ), and some early cytological observations (23, 24) even led to the interpretation that the chromatid is four-stranded. Furthermore, radiation studies on the types of induced chromosomal aberrations have indicated that, in late prophase and metaphase, an aberration can be induced that ostensibly represents the interaction of but half chromatids, again indicating that the chromatid is at least two-stranded $(5,6,7,14,15,24,27,31,32$, $38,39,46)$. Similar conclusions regarding the strandedness of the chromosome were reached by Read (26) and Steffenson (37), who calculated the numbers of strands required to organize the DNA of the cell into the observed length of the chromosomes (see also 35).

Electron microscopy has not settled the problem; different observers have obtained preparations that could be interpreted as representing either a multistranded (28) or a single-stranded chromosome (20; see also 4, 21, 22).

The strongest evidence indicating that the 
chromosome might be single-stranded comes not from direct cytological observation of the number of strands, but from experiments designed to elucidate chromosome structure. Gall (10) has studied the kinetics of DNase action in breaking lampbrush chromosomes of the newt. He has found that, within the loops, DNase breaks chromosomes with approximately two-hit kinetics. This is interpreted as indicating that in the loop the chromosome consists of but a single molecule of double-stranded DNA; i.e., the loop is singlestranded. In the interloop regions of the lampbrush chromosome where the strands from two loops come together, breaks are produced with about four-hit kinetics. Taylor et al. (44) found by the use of autoradiographic methods that, after one round of chromosomal duplication in the presence of tritiated thymidine (which is incorporated into DNA), both chromatids are labeled at the first succeeding metaphase, but that only one chromatid of a chromosome is labeled at the second succeeding metaphase. This is a clear demonstration that the distribution of labeled DNA to the daughter chromatids follows a semiconservative pattern and is reminiscent of semiconservative replication of DNA itself (19). Although it can be argued that a semiconservative distribution is not necessarily a reflection of semiconservative replication of DNA, the simplest interpretation of these experiments is that the pattern of distribution does indeed reflect the pattern of replication.

Gall's and Taylor's strong evidence regarding the strandedness of the chromosomes has not gone unchallenged, however. Sapp (30), for instance, has observed with the electron microscope that the loops of the lampbrush chromosomes appear multistranded. Furthermore, he finds that, after DNase treatment, what may be scored with the light microscope as breaks in the loop are frequently seen to be connected by submicroscopic fibrils when viewed with the electron microscope. Peacock (25) recently repeated Taylor's autoradiographic studies and found that, although the majority of the chromosomal label is distributed in the fashion discovered by Taylor, very frequently two chromatids at the second division are labeled at the same level, i.e., are isolabeled. This has led him to believe that the chromosomes consist of at least two strands.

This paper presents results of experiments in which fixed isolated chromosomes were treated with various enzymes in an attempt to loosen the chromosome and so elucidate chromosome structure. The somatic chromosomes in Vicia root tip cells appear to be multistranded in our cytological preparations. The changes brought about by enzyme digestions therefore supplement other cytological, radiation, and autoradiographic evidence that the mitotic chromosome is multistranded.

\section{MATERIALS AND METHODS}

Lateral root tips of Vicia faba were used in all experiments. Seeds of Vicia faba, Sutton's Exhibition Long Pod, were soaked, peeled, and germinated between layers of cotton batting; for actual details, see Wolff (47). When the primary roots were $3 \mathrm{~cm}$ long, the root tips were cut off and the seeds suspended with their roots in aerated spring water. Lateral roots were obtained 9 days from the beginning of soaking. In order to obtain large numbers of chromosomes, mitosis in the root tips of the seedlings was partially synchronized with 5-aminouracil according to the methods of Smith et al. (34). Seedlings were put into a solution of 5-aminouracil (0.75 gm per liter) for 24 hours, washed in running tap water for 15 minutes, then allowed to recover in aerated spring water. A peak of mitosis (mitotic index around 40 per cent) usually occurred 12 hours after removal from 5aminouracil. The beans were placed with their root tips in a 0.01 per cent colchicine solution 7 hours after removal from 5-aminouracil and kept there for 7 hours to collect a large number of cells in metaphase. The use of colchicine brought the mitotic index to about 70 per cent.

The meristematic regions of the roots were cut off and fixed in cold 2 per cent neutral formalin for 1 hour (18). The fixed tissue (approximately $1 \mathrm{gm}$ ) was homogenized in a mortar. The homogenate was taken up with 0.01 м phosphate buffer $(\mathrm{pH} \mathrm{7.0)}$, then filtered through two layers of Miracloth (supplied by Chicopee Manufacturing Co., Milltown, New Jersey) to remove most of the debris. The filtrate was centrifuged at $150 \mathrm{~g}$ for 5 minutes in an International PR-2 centrifuge, and the supernatant discarded. The pellet was washed by resuspending it in a cold phosphate buffer $(0.01 \mathrm{M}, \mathrm{pH} 7.0)$ and recentrifuged at $150 \mathrm{~g}$ for 5 minutes. This latter procedure was repeated four times. The final pellet primarily contained free nuclei and clumped metaphase chromosomes.

The pellet of nuclei and chromosomes was subdivided and resuspended in buffer for treatment with various enzyme solutions. The enzyme solutions were: (a) $0.1 \mathrm{mg}$ trypsin per $\mathrm{ml}$ of $0.01 \mathrm{M}$ phosphate buffer at $\mathrm{pH} 7.2 ;(b) 1.0 \mathrm{mg}$ DNase per $\mathrm{ml}$ of $0.003 \mathrm{M} \mathrm{mag-}$ nesium sulfate in $0.01 \mathrm{M}$ phosphate buffer at $\mathrm{pH} 6.8$; (c) $1.0 \mathrm{mg}$ RNase per $\mathrm{ml}$ of $0.01 \mathrm{M}$ phosphate buffer 

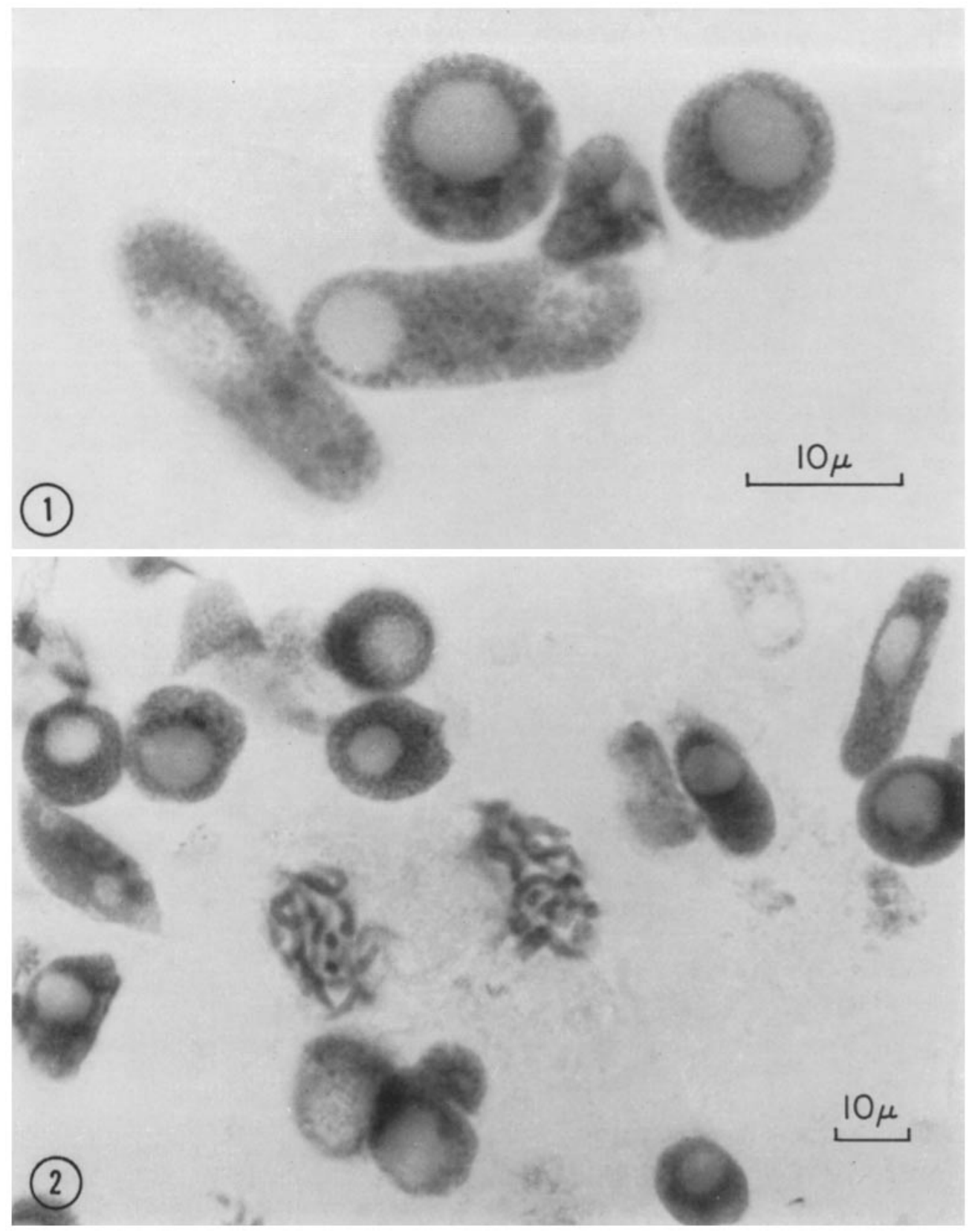

Figure 1 Feulgen-stained isolated Vicia faba nuclei. $\times 2,100$.

Figure 2 Feulgen-stained isolated Vicia faba nuclei and chromosomes. $\times 1,000$.

at $\mathrm{pH} 7.0 ;(d) 1 \mathrm{mg}$ pepsin per $\mathrm{ml}$ of $0.1 \mathrm{~N} \mathrm{HCl}$ at $\mathrm{pH}$ 1.3. One drop of the buffer containing isolated nuclei and chromosomes was placed on a subbed microslide and mixed with three drops of the enzyme solution.
Control solutions made up in the same way without the enzymes were also used. The slides were placed in a moist chamber consisting of a covered Petri dish containing moistened filter paper and incubated at 
TABLE I

Effect of Various Enzymes on Isolated Nuclei and Chromosomes of Vicia faba

\begin{tabular}{|c|c|c|c|c|}
\hline Treatment & $\begin{array}{l}\text { Alkaline fast } \\
\text { green }\end{array}$ & $\begin{array}{l}\text { Feulgen } \\
\text { re- } \\
\text { action }\end{array}$ & $\begin{array}{l}\text { Azure B } \\
\text { (purple) }\end{array}$ & Appearance of treated nuclei and chromosomes \\
\hline $\begin{array}{l}\text { Trypsin (short hydroly- } \\
\text { sis) }\end{array}$ & $-{ }^{*}$ & + & + & $\begin{array}{l}\text { Chromosomes elongated and split into half } \\
\text { chromatid strands; nuclear matrix removed, } \\
\text { leaving reticular skeleton }\end{array}$ \\
\hline Trypsin (long hydrolysis) & - & + & + & Structural integrity completely disrupted \\
\hline DNase & + & - & $+\ddagger$ & Chromosomes swollen, but seemingly intact \\
\hline RNase & + & + & $-\ddagger$ & No apparent change in structure \\
\hline Pepsin & - & + & & Chromosomes and nuclei slightly shrunken \\
\hline
\end{tabular}

* Alkaline fast green-stained, trypsin-treated chromosomes exhibit no demonstrable stain; yet, under phase optics, nuclear skeletons and chromosomes are intact (DNA is removed by the hot TCA hydrolysis used in this staining procedure). - , negative staining reaction; + , positive staining reaction.

$\ddagger$ Azure B is a metachromatic stain. After DNase the preparations stained purple with azure B; after RNase they stained blue-green.

$35^{\circ} \mathrm{C}$ for 30 minutes. At the end of this time, the slides were air dried and stained for DNA by the Feulgen procedure, for RNA with azure B (9), or for histones by the alkaline fast green method (1). The latter procedure was slightly modified in that the material was hydrolyzed in 5 per cent trichloroacetic acid (TCA) for 1 hour instead of 15 minutes.

RESULTS AND DISCUSSION

The isolation procedure gave preparations of nuclei that were relatively free of cytoplasmic contamination (Fig. 1). Fig. 2 shows a portion of the preparation containing both free nuclei and clumped metaphase chromosomes that are caught in cytoplasm.

Table I presents a summary of the effects of various enzyme treatments.

The interphase nuclei and chromosomes were treated with trypsin and watched under the microscope. With time the nuclei became progressively less refractile, so that eventually they could not be seen with the light microscope. The enzyme seemed to digest some of the material in these nuclei. The nucleoli disappeared, leaving trypsin-resistant cores (nucleolini?). After $30 \mathrm{~min}-$ utes treatment and air drying, the nuclei stretched to about three times their original diameter. The clumped metaphase chromosomes also separated from one another and stretched by a factor of 3 $(9 \mu$ to $27 \mu$, cf. Fig. $5 a$ and $b$ ). Although the refractive index of the unstained material changed so that the chromosomes and nuclei became invisible with bright field optics, they were still there, as could be seen by phase contrast micros- copy. After enzyme treatment, the interphase and prophase nuclei that had been digested and stretched showed clearly a network of fibers within the nucleus (Figs. 3 and 4). Since the nuclei no longer appeared fairly homogeneous but showed this network, we termed these figures nuclear skeletons. Similar reticulation has been observed in both living and fixed plant nuclei (see 8 ).

When metaphase chromosomes are stretched after treatment with trypsin, we find that, upon air drying, the chromatids consist of two strands or half chromatids relationally coiled about each other. The enzyme treatment evidently reduces the numbers of coils, and in many instances we have found that the two half chromatids lie essentially side by side (Figs. 5 and 6 ). In certain favorable cases (Fig. 6), we can see that each half chromatid in itself seems to be composed of two interwound strands, indicating that as seen at the light microscope level the chromatid could be at least quadripartite (see also 2, 11). Occasional preparations are obtained in which the uncoiling has gone on to such an extent that we find the chromatids bifurcating. We have been able to follow some of these bifurcations to a point at which we can see the four parts of the individual chromatid (Fig. 7).

The skeletons and elongated chromosomes left behind after trypsin digestion are fast green negative, indicating that most of their histones have been removed; they are Feulgen positive, indicating that the DNA is still present. Some DNA has been released from the nuclei and chromo- 


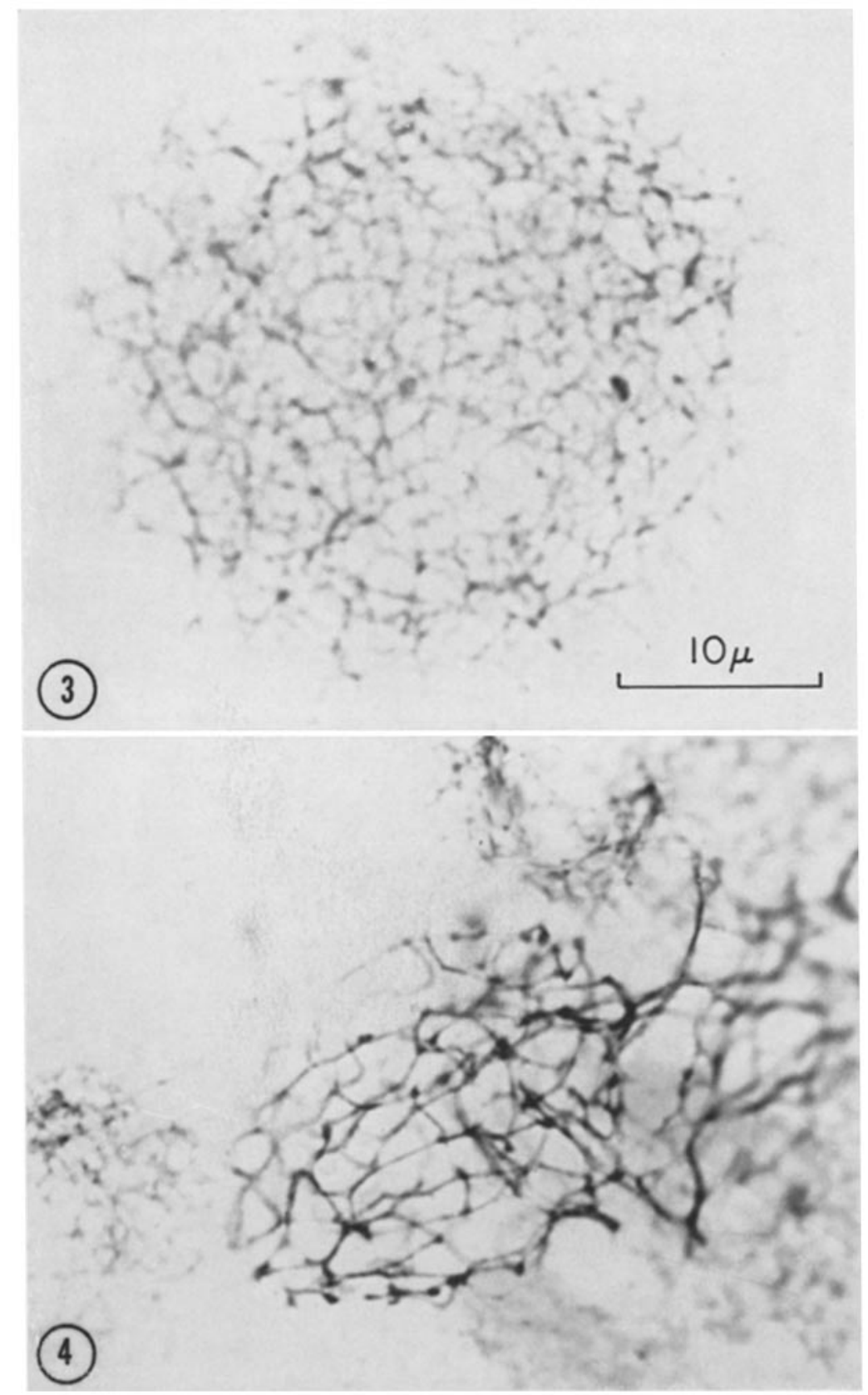

FiguRe 3 Feulgen-stained, mildly trypsin-treated isolated nucleus showing skeleton. $\times 2,500$.

Figure 4 Feulgen-stained, mildly trypsin-treated early prophase nucleus. $\times 1,370$.

somes, however, as evidenced by the fact that in the Feulgen preparations the general background is now light pink. In those trypsin-treated preparations that were stained with fast green, the DNA was removed by a I-hour hydrolysis in hot $\left(90^{\circ} \mathrm{C}\right)$ 5 per cent TCA. These preparations were Feulgen negative, azure $B$ negative, and fast green negative, yet the skeletons and chromosomes could still be 


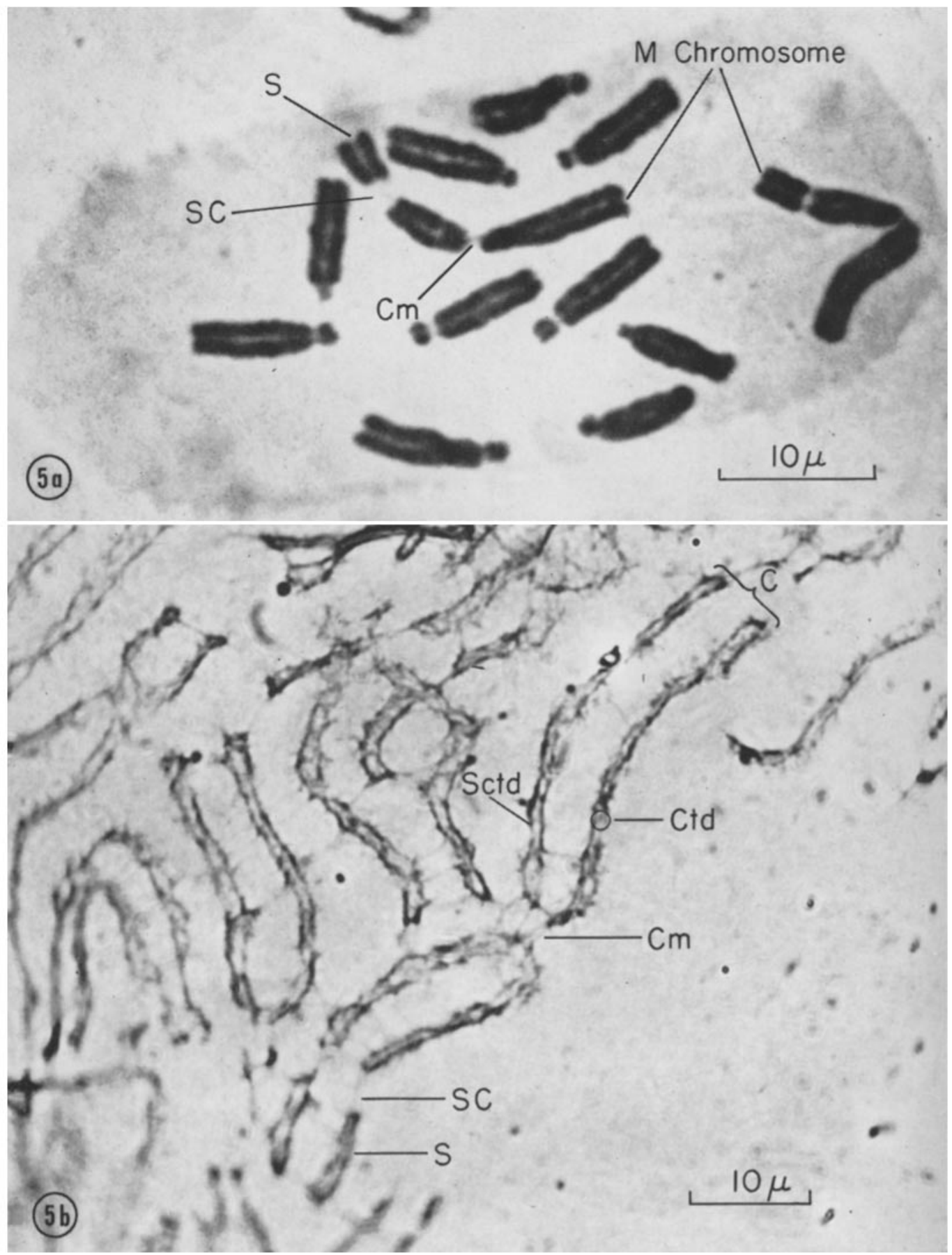

Figure 5 a Normal Vicia faba chromosome complement at metaphase. Abbreviations as in Fig. $5 b$. $\times 2,200$.

Figure $5 b$ Feulgen-stained, trypsin-treated isolated metaphase chromosomes. The $\mathbf{M}$ chromosome $(C)$ is seen with each of its chromatids $(C t d)$ split into two half chromatids (Sctd). The satellite $(S)$, secondary constriction $(\mathrm{SC})$, and centromere $(\mathrm{Cm})$ are also visible. $\times 1,800$. 


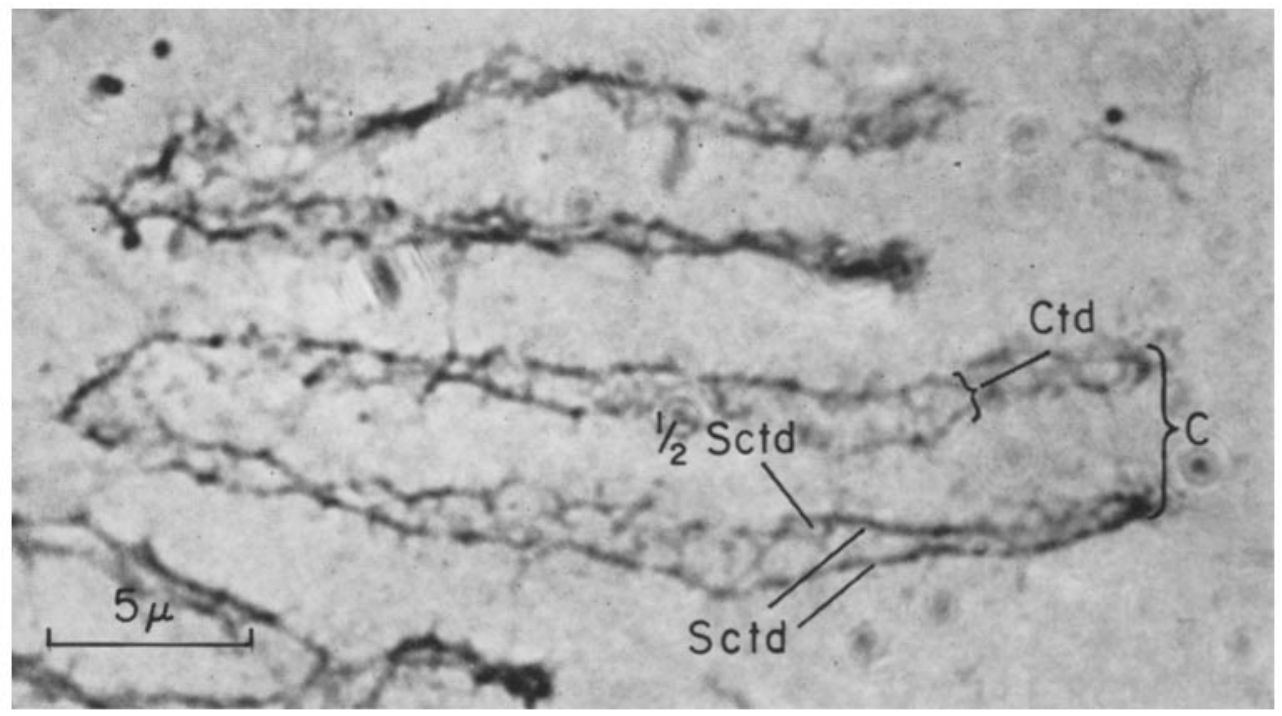

Figure 6 Feulgen-stained isolated metaphase chromosomes. Abbreviations as in Figs. $5 b$ and 7 . $\times 4,000$.

seen when phase contrast microscopy was used. Although at first sight the evidence might indicate that DNA does not appear to be the architectural component upon which the linear continuity of the skeletons and chromosomes depends, it should be remembered that the enzyme treatment was carried out after formalin fixation. Fixation could cause cross-linking between proteins and the formation of a new continuous protein framework.

In spite of the observation that pepsin treatment, which leds to negative alkaline fast green preparations, does not appreciably affect the morphology of the nuclei and chromosomes, the stretching and splitting of nuclei and chromosomes after trypsin hydrolysis still may be caused by removal of histones. The pepsin solution, which contains $0.1 \mathrm{~N} \mathrm{HCl}$, may also precipitate some spindle or cytoplasmic protein on the chromosomes. Furthermore, acid usually causes shrinking of chromatin. This pretreatment with acid might be responsible for the lack of swelling and strand separation even though histones are removed.

Similarly, DNase and RNase treatments, which remove both DNA and RNA as shown by Feulgen negativity or azure B negativity of the resultant slides, do not appreciably affect nuclear or chromosome morphology. Because there is a considerable amount of cytoplasm encasing the clumped chromosomes, however, any possible fragmenta- tion of the chromosome by DNase or RNase might not be detected.

The present experiments can be interpreted to indicate that protein contributed to the linear continuity of these mitotic chromosomes and that the chromosome is a multistranded structure that is embedded in a matrix of non-histone protein.

The regular appearance of multistranded chromatids at metaphase confirms the observations made with the light microscope in the past. For instance, Kaufmann (12) and Nebel $(23,24)$ observed at least two and on occasion four strands in a chromatid; Manton (17) found the chromatids of the fern Todea to be bipartite; and GimenezMartin et al. (11) found that the chromatids of Sicilla consist of two interwoven strands. Their pictures show coiling similar to that seen in Fig. 6. The extensive uncoiling that occurs after trypsin treatment in the present experiments, however, can lead to a total unwinding of the chromatid strands.

Taylor (42) has proposed a model of the chromosome, based on Freese's model, that could explain the appearance of half chromatids in a chromosome that is basically single-stranded. The model consists of two parallel chains of links (Taylor's $\mathbf{R}$ linkers). These are interconnected by a runglike arrangement of DNA molecules. Under some conditions, if only the two parallel chains of $\mathrm{R}$ links were observable, the chromatid would 


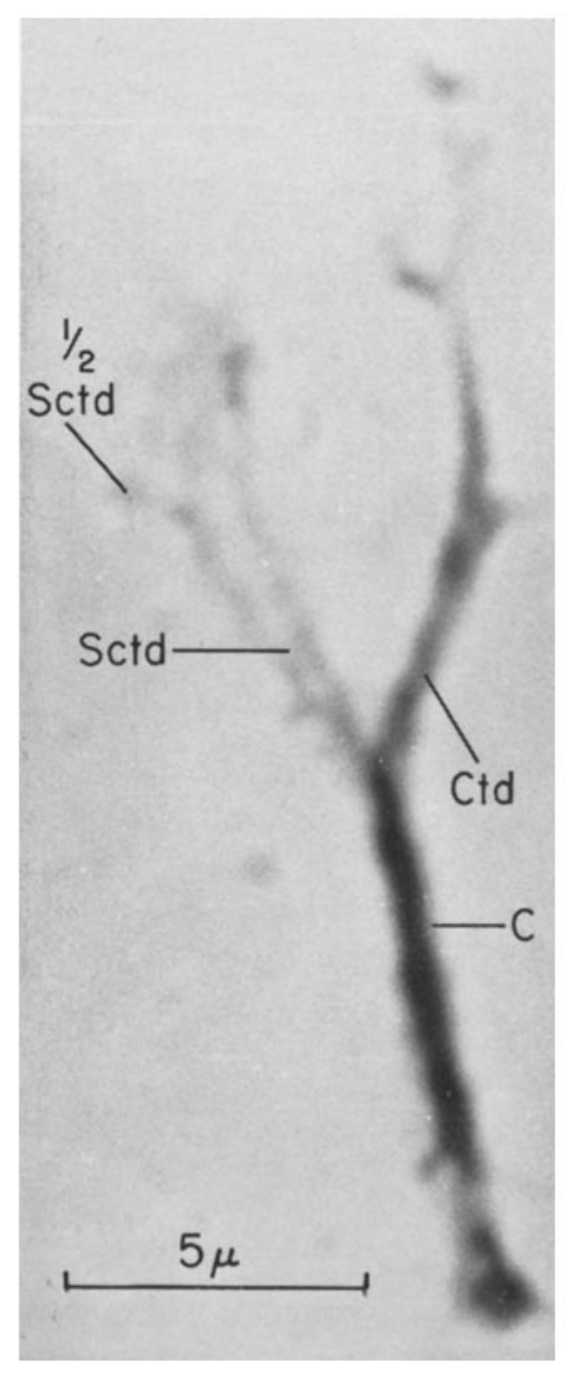

Figure 7 Feulgen-stained, mildly trypsin-treated metaphase chromosome $(C)$ showing one chromatid $(C t d)$ separated into half chromatids (Sctd), with each of these bifurcating into quarter chromatids $(1 / 2 \mathrm{Sctd})$. $\times 6,000$.

appear bipartite. The appearance of four strands within a chromatid, however (Fig. 6), and the appearance of doubly bifurcating chromatids (Fig. 7) do not seem to be consistent with such a model.

The appearance of multistranded chromatids not only is consistent with previous observations of chromosomes, but also fits results of radiation experiments in which half chromatid aberrations were induced. It does not, however, fit the observations of Gall (10) on the kinetics of DNase-induced breaks of the lampbrush chromosome. Nor do the results of our enzyme digestions parallel the results obtained by MacGregor and Callan (16) on the lampbrush chromosome, in which they found that DNase can break chromosomes. We are left to wonder whether the meiotic lampbrush chromosome differs from the usual mitotic chromosome observed in plants (and animals). If one makes a balance sheet, it seems that all pertinent observations with the light microscope $(2,11,12$, $17,23,24,28,38,46$ ) indicate that the mitotic chromosome is multistranded, whereas experiments on the lampbrush chromosome do not necessarily fit this pattern $(10,16$; see, however, 28).

The semiconservative distribution of DNA into daughter chromatids, as first discovered by Taylor et al. (44), is simple to visualize in terms of a single-stranded chromatid, i.e., a chromatid consisting of but one double-stranded DNA molecule. It is somewhat more difficult, but not impossible, to make a scheme whereby a chromatid that consists of more than one DNA double helix distributes its label so that both chromatids would be labeled at the first division, and that only one chromatid would be labeled at any successive division. Schwartz (33), Steffenson (36), Cavalieri and Rosenberg (3), and Peacock (25) have presented such schemes. In Fig. 8 we present a model that can account for the segregation of label among daughter chromatids when the chromatid is multistranded. The model is similar to one proposed by Uhl (45) to explain crossing-over. In our model, several strands of DNA run side by side longitudinally between links. Upon replication, each strand of the double-stranded DNA helix is attached to opposite sides of the plane of splitting of the link. After one round of replication in label, each strand will appear labeled. If these chromatids now replicate in the absence of label, all the labeled DNA will be in one chromatid, whereas the sister chromatid will be completely unlabeled.

We do not intend that this model be taken as an indication that we believe the chromosome to be constructed in this fashion. The model in Fig. 8 obviously does not include all the features which our data indicate to be necessary. It only demonstrates that, in the absence of any critical knowledge of how a chromosome is constructed, it is easy to conceive of an arrangement of DNA in a multistranded chromosome that could give the results first observed by Taylor and his co-workers, 


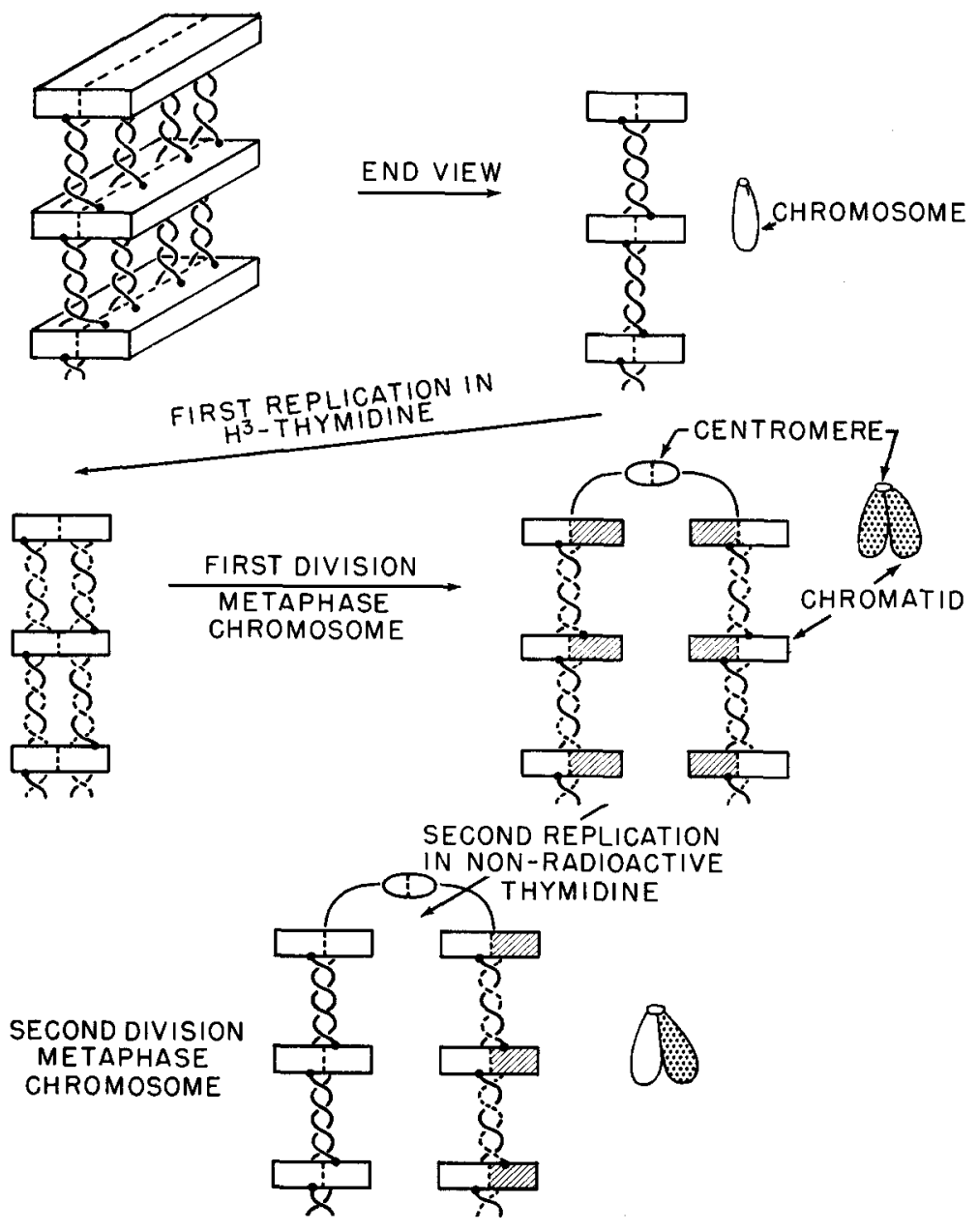

FIGURE 8 Model showing that it is topologically possible for a multistranded chromosome to segregate labeled and unlabeled DNA at the second division after labeling with tritiated thymidine. In the model, four strands of DNA run from link to link along the length of the chromosome. Heavy lines indicate the original DNA. Dotted lines indicate radioactive DNA.

results that must be considered in any hypothetical formulation of chromosome structure. It is interesting to note, however, that the model bears marked similarities to the structure of the chromosome proposed by $\mathrm{R}$ is (28), in which he had DNA running from link to link in the chromosome.

The concept of a cytologically multistranded chromosome makes it difficult to visualize many genetic phenomena, such as mutagenesis and crossing-over. Of course, a cytologically multistranded chromosome need not be genetically multistranded. The fact that it is more difficult to think of genetic processes in terms of multistranded than of single-stranded chromosomes, however, does not constitute evidence that the chromosome is single-stranded.

Research sponsored by the United States Atomic Energy Commission under contract with the Union Carbide Corporation.

Received for publication, October 13, 1964. 


\section{REFERENCES}

1. Alfert, M., and Geschwind, I., A selective staining method for the basic protein of cell nuclei, Proc. Nat. Acad. Sc., 1953, 39, 991.

2. Brooke, J. H., Jenkins, D. P., I.awson, R. K., and Osgood, E., Human chromosome uncoiling and dissociation, Ann. Human Genet., 1962, 26, 139.

3. Cavalieri, L. F., and Rosenberg, B. H., The replication of DNA. III. Changes in the number of strands in $E$. coli DNA during its replication cycle, Biophysic. J., 1961, 1, 337.

4. Cole, A., and Somers-Cronenwett, C., Electron microscopic studies of isolated mammalian metaphase chromosomes, 8th Annual Meeting of Biophysical Society (Chicago), 1964, abstract No. WC3.

5. Conger, A. D., X-ray sensitivity of the stages of mitosis, Am. J. Bot., 1947, 34, 582.

6. Crouse, H. V., X-ray breakage of lily chromosomes at first meiotic metaphase, Science, 1954 , 119, 485.

7. Davidson, D., The irradiation of dividing cells. I. The effects of $x$-rays on prophase chromosomes, Chromosoma, 1957, 9, 39.

8. Denues, A. R. T., Chromosomes: Their constitution and function, in Frontiers in Cytology, (S. Palay, editor), New Haven, Yale University Press, 1958, 42.

9. Flax, M., and Himes, M., Microspectrophotometric analysis of metachromatic staining of nucleic acids, Physiol. Zool., 1952, 25, 297.

10. Gall, J. G., Kinetics of deoxyribonuclease action on chromosomes, Nature, 1963, 198, 36.

11. Gimenez-Martin, G., Lopez-Saez, J. F., and Gonzalez-Fernandez, A., Somatic chromosome structure, Cytologia, 1963, 28, 381 .

12. Kaufmann, B. P., Chromonemata in somatic and meiotic mitoses, Am. Naturalist, 1931, 65, 280.

13. Kaufmann, B. P., Gay, H., and MaDonald, M., Organizational patterns within chromosomes, Internat. Rev. Cytol., 1960, 9, 77.

14. La Cour, L. F., and Rutishauser, A., Chromosome breakage experiments with endosperm: Sub-chromatid breakage, Nature, 1953, 172, 501 .

15. La Cour, L. F., and Rutishauser, A., X-ray breakage experiments with endosperm. I. Sub-chromatid breakage, Chromosoma, 1954, 6, 696 .

16. MacGregor, H. C., and Callan, H. G., The actions of enzymes on lampbrush chromosomes, Quart. J. Micr. Sc., 1962, 103, 173.

17. Manton, I., New evidence on the telophase split in Todea barbara, Am. J. Bot., 1945, 32, 342.

18. MaLeish, J., Quantitative relationships between deoxyribonucleic and ribonucleic acid in isolated plant nuclei, Proc. Roy. Soc. London, Series B, 1963, 158, 261.

19. Meselson, M., and Stahl, F., The replicating of DNA in Escherichia coli, Proc. Nat. Acad. Sc., $1958,44,671$.

20. Miller, O. L., JR., 1964, personal communication.

21. Moses, M. J., Radioisotope studies of chromosome structure, in Radiation-Induced Chromosome Aberrations, (S. Wolff, editor), New York, Columbia University Press, 1963, 155.

22. Moses, M. J., The nucleus and chromosomes: A cytological perspective, in Cytology and Cell Physiology, (G. H. Bourne, editor), New York, Academic Press, 1964, 423.

23. Nebel, B. R., Chromosome structure in Tradescantiae. I. Methods and morphology, Z. Zellforsch. u. mikr. Anat., 1932, 16, 251.

24. Nebet, B. R., Chromosome structure. XII. Further radiation experiments with Tradescantia, Am. J. Bot., 1937, 24, 365 .

25. Pracock, W. J., Chromosome duplication and structure as determined by autoradiography, Proc. Nat. Acad. Sc., 1963, 49, 793.

26. READ, J., Chromosome size, structure and radiation damage, in Effects of Ionizing Radiation on Seeds (International Atomic Energy Agency, Kaerntnerring, Vienna), 1961, p. 217.

27. ReEs, H., Centromere control of chromosome splitting and breakage, Heredity, 1953, 6, suppl., 235.

28. Ris, H., The annual mutation lecture: Ultrastructure and molecular organization of genetic systems, Can. J. Genet. Cytol., 1961, $3,95$.

29. Ris, H., and Chandler, B. L., The ultrastructure of genetic systems in prokaryotes and eukaryotes, Cold Spring Harbor Symp. Quant. Biol., 1963, 28.

30. SAPP, W. J., 1964, personal communication.

31. SAX, K., The effect of ionizing radiation on chromosomes, Quart. Rev. Biol., 1957, 32, 15.

32. SAx, K., and KING, E. D., An x-ray analysis of chromosome duplication, Proc. Nat. Acad. Sc., 1955, 41, 150.

33. Schwartz, D., Deoxyribonucleic acid side-chain model of the chromosomes, Nature, 1958, 181, 1149.

34. Smith, H. C., Fussell, C., and Kugelman, B., Partial synchronization of nuclear division in root meristem with 5-aminouracil, Science, $1963,142,595$.

35. Stahl, F. W., The Mechanics of Inheritance, Englewood Cliffs, Prentice-Hall, 1964, 61. 
36. Steffensen, D., A comparative view of the chromosome, Brookhaven Symp. Biol., 1959, $12,103$.

37. Steffensen, D., Chromosome structure with special reference to the role of metal ions, Internat. Rev. Cytol., 1961, 12, 163.

38. Swanson, C. P., Differential sensitivity of prophase pollen tube chromosomes to $\mathrm{x}$-rays and ultraviolet radiation, J. Gen. Physiol., 1943, 26, 485.

39. Swanson, C. P., X-ray and ultraviolet studies on pollen tube chromosomes. II. The quadripartite structure of the prophase chromosome of Tradescantia, Proc. Nat. Acad. Sc., 1947, 33, 229.

40. TAYlor, J. H., The time and mode of duplication of chromosomes, Am. Naturalist, 1957, 91, 209.

41. TAYLOR, J. H., Autoradiographic studies of chromosome duplication and structure, Oklahoma Conference on Radioisotopes in Agriculture, United States Atomic Energy Commission, TID-7578, 1959, 123.
42. Taylor, J. H., Chromosome reproduction, Internat. Rev. Cytol., 1962, 13, 39.

43. TAYLOR, J. H., The replication and organization of DNA in chromosomes, in Molecular Biology, (J. H. Taylor, editor), New York, Academic Press, Inc., 1963, 65.

44. Taylor, J. H., Woods, P. S., and Hughes, W. L., The organization and duplication of chromosomes as revealed by autoradiographic studies using tritium-labeled thymidine, Proc. Nat. Acad. Sc., 1957, 43, 122.

45. UHL, C., Chromosome structure and crossing over, Genetics, 1965, 51, 191.

46. Wilson, G. B., Sparrow, A. H., and Pond, V., Sub-chromatid rearrangements in Trillium erectum. I. Origin and nature of configuration induced by ionizing radiation, Am. J. Bot., 1959, 39, 309.

47. WolfF, S., Handling of root tips, in Methods in Cell Physiology, (D. Prescott, editor), New York, Academic Press, Inc., 1964, chap. 12. 